\author{
Veronica Lambert \\ School of nursing and human sciences, Dublin City University, Ireland
}

\title{
Design of paediatric hospitals
}

The impact of healthcare environments on children and young people's (CYP) health and psychosocial wellbeing has attracted much attention in recent years. This sits within the realm of the political drive for enhanced awareness of the need to take account of the rights and voice of the child. Perhaps as a direct result of the United Nations Convention on the Rights of the Child, and recognition from evidence in adult population studies of the impact of healthcare environments on psychosocial healing, contemporary times have witnessed a discernible movement towards enhancing quality care by promoting child and adolescentfriendly hospital environments. The Council of Europe guidelines on child-friendly health care moved to place the rights and needs of children at the heart of health care. The Council acknowledges that the delivery of child-oriented services, which includes the notion of family-centred care, should be delivered in child and family friendly environments. However, knowledge about what constitutes a child-friendly healthcare environment from CYP's perspective is often lacking with hospital architectural blueprints predominantly designed around adult proxy-reported assumptions about the needs and desires of children.

CYP's opinions must be taken into account by hospital environmental design planners if healthcare spaces aspire to being CYP and family friendly. This is important because previous evidence has demonstrated that children's priorities and preferences for hospital design may differ to those of adults. The content of this presentation has been informed by previous participatory art-based work that investigated young children's (aged five to eight years) perspectives of hospital physical places and social spaces to inform the design of the built environment of a new children's hospital; alongside the conduct of a scoping review of the literature with a particular focus on studies examining CYP's perspectives of hospital environmental design. Core themes that will be discussed include first impressions and architectural scale on entering the hospital building; entrapment, way finding, free movement and having a sense of space; entertainment, socialisation and connectivity; communal, family, personal and private spaces; having access to the outside world; and a preference for interior designs that are aesthetically pleasing and epitomise modern, creative, colourful, imaginative and comfortable décor.

These themes are important for nurses, clinicians' environmental designers, policymakers and other stakeholders to consider because they represent what a supportive child healthcare environment should constitute from the perspective of children themselves. A challenge for hospital environmental designers is how to ensure CYP's voices are translated into the hospital architectural blueprint, as many factors can impede the creation of an ideal child-friendly hospital environment; most notably, the desire to meet the wishes of multiple stakeholders. A key recommendation for clinicians caring for CYP in hospital is to find ways to appropriately enact an environment that promotes CYP's independence and locus of control. 